\title{
STUDY OF ACCESSORY SUPRAORBITAL FORAMEN IN NORTH INDIAN HUMAN SKULL
}

\author{
KAMTA P NIRALA, AMRITA GUPTA, SAGUN SHUKLA, SUBHASH GUPTA*
}

Department of Anatomy, Varun Arjun Medical College, Shahjahanpur, Uttar Pradesh, India. Email: guptadrsubhash819@gmail.com

\author{
Received: 25 September 2020, Revised and Accepted: 15 January 2021
}

\section{ABSTRACT}

Objective: This research was aimed at telling the anatomical characteristics of the accessory supraorbital foramen (ASOF) in relation to the main supraorbital foramen (SOF), which is necessary in clinical situations that require regional surgical procedures.

Methods: A total dedicated to the presence and location of 72 dry Indian adults of unknown age and sex were investigated. In each skull, the ASOF location was measured on both sides with a Vernier caliper metal case, with the SOF as the reference point. The total number of accessory foramen was also noted.

Results: Accessory infraorbital foramens (IOFs) were seen only in 4.16\% in our study and all seen were single in number. Half of those accessory foramen were present on medial and rest half were present on superomedial position as compared to the main IOF. Half among present accessory foramens were located at a distance of $<2 \mathrm{~mm}$ and half were located at a distance of more than $2 \mathrm{~mm}$. The mean location of accessory IOF was at $7.07 \mathrm{~mm}$ from main IOF.

Conclusion: Knowledge of the anatomical characteristics of ASOF can have major effects on surgical and local anesthetic preparation blockage of the super orbital nerves. Additional guidance for surgeons may be provided with information on the foramens obtained from this study. The surgeons should note this during the nerve block as damage to either branch will lead to sensory impairment and incomplete blocking of the nerve.

Keywords: Human skull, Accessory supraorbital foramen, Anatomical, Indian.

(c) 2021 The Authors. Published by Innovare Academic Sciences Pvt Ltd. This is an open access article under the CC BY license (http://creativecommons.org/ licenses/by/4.0/) DOI: http://dx.doi.org/10.22159/ajpcr.2021v14i3.39863. Journal homepage: https://innovareacademics.in/journals/index.php/ajpcr

\section{INTRODUCTION}

The foramina of the facial, which transmits blood and nerves between the facial structures and the cranium, shows functional and metric features which are different from those found in standard anatomy textbooks [1,2]. Supraorbital nerves are also used in a variety of maxillofacial procedures, including facial wound closure, biopsies, scar revision, cosmetic skin procedures, as well as in various endoscopy procedures, commonly used for cosmetic facial activity [3,4]. Excessive dissection and retraction around such neurovascular bundles may trigger scarring, which could result in impounding neuropathy and severe neuralgia $[5,6]$.

The supraorbital nerve supplies forehead and scalp region. It exits through supraorbital foramen (SOF) and may be injured during various surgical and anesthetic procedures [7]. In about two-third of cases, supraorbital margin has notch, and in one-third of cases, this passage is converted into foramen by ossification of the periosteal ligament crossing the notch. In cases of the absence of supraorbital passages (foramen/notch), or presence of accessory SOF (ASOF), the supraorbital vessels and nerve are prone to injury. This block is approved out in the treatment of migraine and chronic paroxysmal hemicranias, as alternative but temporary treatment for super-arbitrary neuralgia and other cosmetic skin treatments, removal of facial fractures, biopsies, and scar revisions.

The foramen was described by a number of reviews on surgical anatomy of the orbit as lying medial, superomedial, and inferomedial to main SOF. The direction of ASOF is important to know when moving the needle to block the nerve. For this reason, the study was conducted to assess the presence, orientation, and location of the ASOF with respect to one of the surgically encountered anatomical landmarks SOF in North Indian dry adult skulls.
To study the morphological and topographical anatomy of the ASOF in relation to the SOF which is necessary in clinical situations, an effort was made to study the location of ASOF from surgically important reference points in this area. These data would provide important information for local anesthesia during maxillofacial and plastic surgery.

\section{METHODS}

Type of study

This was a museum-based cross-sectional observational study.

\section{Place of study}

This research was conducted in the Department of Anatomy, Varun Arjun Medical College, Banthara, Shahjahanpur. Skulls from museum of the Anatomy Department of RHMC, Bareilly, were also included in the study.

Duration of study

It was a horizontal study during November 2019-June 2020

\section{Study samples}

Seventy-two dry human adult skulls of unknown age and sex.

\section{Inclusion criteria}

Human dry skulls complete in all respects were included in the study.

\section{Study tool}

Single observer using a metal casing Vernier caliper with an accuracy of up to $0.01 \mathrm{~mm}$, transparent scale, double tip compass.

\section{Study technique}

Single observer method.

\section{Analysis of data}

Data obtained were collected and analyzed statistically using SPSS software and Microsoft Excel 2007. 


\section{Methodology}

Measurements were taken after taking permission from the relevant authorities. In each skull, the ASOF on both sides was measured using a metal casing Vernier caliper, with the SOF as the reference point. The SOF's location and orientation of the ASOF were also documented.

\section{RESULTS}

Majority, 49 (68.1\%) on the left (LT) and 48 (66.7\%) on the right (RT) side of skulls in our study had no ASOF. Single accessory foramen was found in $3(4.2 \%)$ skulls on the LT (Table 1) and in $14(19.4 \%)$ on the RT side, whereas double (i.e., Two) accessory foramen was found in 13 (18.1\%) skulls on the LT and in 7 (9.7\%) on the RT side (Table 2). A maximum of three foramen were also found in 7 (9.7\%) skulls on the LT and in $3(4.2 \%)$ on the RT side. Overall, it was seen that $67.36 \%$ had no ASOF, $11.80 \%$ had single accessory foramen, $13.89 \%$ had double, and $6.94 \%$ had three accessory foramen. It was also observed that 42 (58.33\%) skulls had absence of accessory foramen (Table 3) bilaterally; whereas only $4(5.55 \%)$ skulls had bilateral double accessory foramen (Table 4). None of the skulls had bilateral one or three accessory foramen. Rest 26 (36.11\%) had mixed numbers.

The position of ASOF on the LT side was observed to be lateral in 17 $(23.6 \%)$ and medial in $6(8.3 \%)$ as compared to main SOF/supraorbital notch (SON) (Table 5). On the RT side, it was lateral in 20 (27.8\%) skulls and superior in 4 (5.6\%) (Tables 6 and 7). Among accessory foramen, it was found that they lied at a mean distance of $5.29 \mathrm{~mm}$ overall (Table 8).

\section{DISCUSSION}

During some facial foramina procedures, the significance of the anatomical properties of foramina is increased. SOF or notch is situated at the junction of medial $1 / 3$ and lateral $2 / 3$ of the supraorbital margin. The formation of foramen results because of ossification of the periosteal ligament which closes it below [8]. Partial ossification of this ligament causes a slight gap at the lower margin resulting into an incomplete foramen [9]. An understanding of the anatomical location of important maxillofacial foramina is of increased importance with the rising popularity of endoscopic procedures with limited visibility [3].

Mostly, the SON or SOF is located mainly on the frontal bone supraorbital margin. At the intersection of its lateral two-thirds and medial one-third, this margin is interrupted. It transmits nerve and vessels. Supraorbital nerve is the frontal nerve branch, a trigeminal nerve branch of ophthalmic division. It traverses from side to side the SON/SOF and divides to supply the palpebral filaments of the upper eyelid, conjunctiva, and skin of the scalp until the lambdoid suture. Supraorbital artery is a branch of ophthalmic artery. It leaves the orbit through the SON/SOF and divides into superficial and deep branches. The skin and strength of the upper eyelid, brow, and scalp are supplied. The supraorbital vein joins the supratrochlear vein near the medial angle of the eye to form the facial vein [10]. The accurate anatomical location of SOF/SON is vital for both diagnostic and surgical procedures in this region. In recent years, the forehead, coronal, temple, brow copying (blepharoplasty), and endoscopic procedures have gain impetus as substantial components of management of the aging face. Knowledge of the supraorbital region is important for those performing cosmetic surgeries. The injury of supraorbital vessels and nerve may lead to problems such as hematoma configuration in the subgaleal plane; anesthesia or hypoesthesia of the forehead; and ischemia or necrosis of parts of the forehead flap and hair loss [11]. Complete knowledge of the SOF/SON and supraorbital neurovascular bundle is also important during procedures involving the superior orbital wall such as frontal sinus obliteration; orbital decompression; Botox injections; and exploration for the fractures and orbital exoneration. During these procedures, the SOF/SON is used as the orientation points for the measurements of the better orbital wall as they are found constantly close to the superior orbital margin [12]. Irritation, entrapment, and/or density of the supraorbital nerve have been
Table 1: Number of ASOF on the LT side

\begin{tabular}{cllll}
\hline $\begin{array}{l}\text { ASOF (LT) } \\
\text { number } \downarrow\end{array}$ & Frequency & Percent & $\begin{array}{l}\text { Valid } \\
\text { percent }\end{array}$ & $\begin{array}{l}\text { Cumulative } \\
\text { percent }\end{array}$ \\
\hline Valid & & & & \\
0 & 49 & 68.1 & 68.1 & 68.1 \\
1 & 3 & 4.2 & 4.2 & 72.2 \\
2 & 13 & 18.1 & 18.1 & 90.3 \\
$>2$ & 7 & 9.7 & 9.7 & 100.0 \\
Total & 72 & 100.0 & 100.0 & \\
\hline
\end{tabular}

ASOF: Accessory supraorbital foramen; LT: Left

Table 2: Number of ASOF on the RT side

\begin{tabular}{cllll}
\hline $\begin{array}{l}\text { ASOF (RT) } \\
\text { number } \downarrow\end{array}$ & Frequency & Percent & $\begin{array}{l}\text { Valid } \\
\text { percent }\end{array}$ & $\begin{array}{l}\text { Cumulative } \\
\text { percent }\end{array}$ \\
\hline $\begin{array}{c}\text { Valid } \\
0\end{array}$ & 48 & 66.7 & 66.7 & 66.7 \\
1 & 14 & 19.4 & 19.4 & 86.1 \\
2 & 7 & 9.7 & 9.7 & 95.8 \\
$>2$ & 3 & 4.2 & 4.2 & 100.0 \\
Total & 72 & 100.0 & 100.0 & \\
\hline
\end{tabular}

ASOF: Accessory supraorbital foramen; RT: Right

Table 3: Overall number of ASOF

\begin{tabular}{lllll}
\hline No. of ASOF $\downarrow$ & LT & RT & Total & Percent \\
\hline Zero & 49 & 48 & 97 & 67.36 \\
One & 3 & 14 & 17 & 11.80 \\
Two & 13 & 7 & 20 & 13.89 \\
>Two & 7 & 3 & 10 & 6.94 \\
\hline
\end{tabular}

ASOF: Accessory supraorbital foramen; LT: Left; RT: Right

Table 4: Bilateral presence of ASOF

\begin{tabular}{lll}
\hline B/L ASOF $\downarrow$ & Frequency & Percent \\
\hline B/L zero & 42 & 58.33 \\
B/L one & 0 & 0 \\
B/L two & 4 & 5.55 \\
B/L three & 0 & 0 \\
Mixed & 26 & 36.11 \\
\hline
\end{tabular}

ASOF: Accessory supraorbital foramen

Table 5: Location of ASOF as compared to main SOF/SON on LT side

\begin{tabular}{lllll}
\hline $\begin{array}{l}\text { Location of } \\
\text { ASOF (LT) }\end{array}$ & Frequency & Percent & $\begin{array}{l}\text { Valid } \\
\text { percent }\end{array}$ & $\begin{array}{l}\text { Cumulative } \\
\text { percent }\end{array}$ \\
\hline Valid & & & & \\
Lateral & 17 & 23.6 & 23.6 & 23.6 \\
Medial & 6 & 8.3 & 8.3 & 31.9 \\
Absent & 49 & 68.1 & 68.1 & 100.0 \\
Total & 72 & 100.0 & 100.0 & \\
\hline
\end{tabular}

ASOF: Accessory supraorbital foramen; SOF: Supraorbital foramen;

SON: Supraorbital notch; LT: Left

Table 6: Location of ASOF as compared to main SOF/SON on the RT side

\begin{tabular}{lllll}
\hline $\begin{array}{l}\text { Location of } \\
\text { ASOF (RT) }\end{array}$ & Frequency & Percent & $\begin{array}{l}\text { Valid } \\
\text { percent }\end{array}$ & $\begin{array}{l}\text { Cumulative } \\
\text { percent }\end{array}$ \\
\hline Lateral & 20 & 27.8 & 27.8 & 27.8 \\
Absent & 48 & 66.7 & 66.7 & 94.4 \\
Superior & 4 & 5.6 & 5.6 & 100.0 \\
Total & 72 & 100.0 & 100.0 & \\
\hline
\end{tabular}

ASOF: Accessory supraorbital foramen; SOF: Supraorbital foramen;

SON: Supraorbital notch; RT: Right 
considered as frontal triggers of migraine headaches [13]. Corrugator supercilii muscle resection is careful in such patients. As well, during corrugator resection, proper knowledge of anatomical bony relations of emergence of the supraorbital nerve, its course, and branches are vital for the surgeons. Previously, it was considered that the point of emergence of supraorbital nerve was constant [14]. However, it was noticed by various studies that the exit point was repeatedly not at the

Table 7: Location of ASOF in relation to main SOF among present

\begin{tabular}{lllllll}
\hline Parameter $\rightarrow$ & \multicolumn{2}{l}{ Frequency } & & & \multicolumn{2}{l}{ Percent among } \\
\cline { 2 - 3 } \cline { 7 - 8 } & LT & RT & Total & & Presents & Overall \\
\hline Lateral & 17 & 20 & 37 & & 78.73 & 25.69 \\
Medial & 6 & 0 & 6 & & 12.76 & 4.16 \\
Superior & 0 & 4 & 4 & & 8.51 & 2.78 \\
\hline
\end{tabular}

ASOF: Accessory supraorbital foramen; SOF: Supraorbital foramen; LT: Left; RT: Right

Table 8: Mean distance of ASOF among present

\begin{tabular}{lllll}
\hline ASOF & LT & RT & Total & Mean \\
\hline Sides & 23 & 24 & 47 & \\
Cumulative distance & 92.4 & 156.2 & 248.6 & 5.29 \\
(in mm) & & & & \\
\hline
\end{tabular}

ASOF: Accessory supraorbital foramen; SOF: Supraorbital foramen; LT: Left; RT: Right site where expected, that is, at the junction of inner one-third and outer two-third and of the supraorbital rim.

In the present study, it has been found that notches varied from broad, flat designs to narrow keyholes or bilobed forms, whereas the foramina were more uniform and did not differ much in the diameter. SOF was of different shape, with the longer axis lying mostly in the horizontal plane. In our study, the supraorbital passage was found in almost all skulls and of them one-third had accessory passages. Earlier studies demonstrated about two-third incidence of accessory passages [15]. Ongeti et al. [16] reported around 94\% presence of SO passages. Table 9 shows a comparative analysis of different studies.

The occurrence of ASOF is common and is well documented. In our study, small additional openings medial, superior, and lateral to the SOF/SON were observed in $32.64 \%$ of cases. This is relatively on the higher side, compared to that of Northwest Indian population which was approximately $14 \%$ Gupta et al. [7]. Among other reports, Saylam et al. [4] have found them in $21.2 \%$ of cases and Berry et al. [17] observed them in $50 \%$ of cases. As far as location of these accessory foramina is concerned, a majority of the skulls $(27.8 \%$ on the RT side and $23.6 \%$ on the LT side) had ASOF lateral to the SOF/SON. A similar observation was made by Ashwini et al. [15]. However, Gupta observed $84.6 \%$ of them lateral to the SOF/SON. However, Saylam et al. [4] and Cheng et al. [18] have observed most of the accessory foramina medial to the SOF/SON. The accessory foramina transmit the smaller branches of the supraorbital nerve. These smaller ones arise within the orbit

Table 9: Percent presence of ASOF, LT, and RT

\begin{tabular}{|c|c|c|c|}
\hline Parameter $\rightarrow$ (Presence OF SOF/SON) study $\downarrow$ & SOF/SON Yes/No (\%) & Accessory Yes/No (\%) & \\
\hline Our study & 100 & 32.64 (31.9-L; 33.3-R) & 67.36 (68.1-L; 66.7-R) \\
\hline Ashwini et al., 2012 & $66.25(\mathrm{~B} / \mathrm{L}$ in 54.54$)$ & 66.25 & 33.75 \\
\hline Yukio et al., 2009 & \multicolumn{3}{|c|}{ 39.4-44.6 among different Indian population } \\
\hline Gupta, 2008 & & 14 & \\
\hline \multirow[t]{2}{*}{ Ongeti et al., 2008} & 93.3 (RT); 6.7 & & \\
\hline & 94.2 (LT); 5.8 & & \\
\hline Funda et al., 2007 & 3 & & \\
\hline
\end{tabular}

ASOF: Accessory supraorbital foramen; SOF: Supraorbital foramen; SON: Supraorbital notch

Table 10: Overall number of ASOF, on LT

\begin{tabular}{llll}
\hline Parameter (No. of ASOF) $\rightarrow$ study $\downarrow$ & Zero (\%) & One (\%) & Two (\%) \\
\hline Our study & $67.36(68.1-\mathrm{L} ;$ 66.7-R) & $11.80(4.2-\mathrm{L} ;$ 19.4-R) & $13.89(18.1-\mathrm{L} ; 9.7-\mathrm{R})$ \\
Ongeti et al., 2008 & $78.4(\mathrm{RT})$ & $15.5(\mathrm{RT})$ & $6.94(9.7-\mathrm{L} ;$ 4.2-R) \\
& $80.6(\mathrm{LT})$ & $17.3(\mathrm{LT})$ & 6.1 (RT) \\
Apinhasmit et al., 2006 & & 6.6 & 2.3 (LT) \\
\hline
\end{tabular}

ASOF: Accessory supraorbital foramen; LT: Left

Table 11: Bilateral presence of ASOF

\begin{tabular}{|c|c|c|c|c|c|}
\hline Parameter $\rightarrow$ (No. of ASOF) study $\downarrow$ & B/L zero (\%) & B/L one $(\%)$ & B/L two (\%) & B/L more than $2(\%)$ & Mixed (\%) \\
\hline Our study & 58.33 & 00 & 5.55 & 00 & 36.11 \\
\hline Ashwini et al., 2012 & 33.75 & 54.54 - bilateral & & & $45.45 \mathrm{U} / \mathrm{L}$ \\
\hline
\end{tabular}

ASOF: Accessory supraorbital foramen

Table 12: Location of ASOF in relation to main SOF among present, LT, and RT

\begin{tabular}{|c|c|c|c|c|}
\hline \multirow[t]{2}{*}{ Parameter $\rightarrow$ (mean distance of ASOF) study $\downarrow$} & \multicolumn{2}{|c|}{ Among present (in mm) } & \multicolumn{2}{|c|}{ Overall (in mm) } \\
\hline & LT & RT & LT & RT \\
\hline Our study & 4.01 & 6.51 & $1.28 \pm 2.26$ & $2.17 \pm 4.14$ \\
\hline \multirow[t]{3}{*}{ Ashwini, 2012.S-2 } & $9.11 \pm 1.78(\mathrm{M})$ & $8.62 \pm 1.23(\mathrm{M})$ & & \\
\hline & $7.07 \pm 0.53(\mathrm{~L})$ & $8.75 \pm 0.74(\mathrm{~L})$ & & \\
\hline & $3.08 \pm 0.22(\mathrm{~S})$ & $3.3 \pm 0.41(\mathrm{~S})$ & & \\
\hline
\end{tabular}

ASOF: Accessory supraorbital foramen; SOF: Supraorbital foramen; LT: Left; RT: Right 
and are responsible for incomplete analgesia in facial procedures. Tables 10-12 show a comparative analysis of different studies.

\section{CONCLUSION}

The majority of the data in the literature available is based on studies performed in foreign specimens. Our study, on the other hand, described an Indian community that varies in physical construction from the Western population. The analysis of findings from previous research shows a wide difference in the anatomical characteristics of the SOF due to differences in the parameters used and also due to the various populations studied. With a possibility of these characteristics being dependent on population groups, this study makes the morphometric study of these foramina in the population of India relevant. The results showed a large scatter and variability in the different distances of the supraorbital foramen/notch because we analyzed skulls from different geographical areas; individual's precision in measurements; and varying osteoblastic and osteoclastic activity in different individuals. The varying average distances together with the standard deviation as described in the tables specify the precise position of the SOF, SOF/SON in Indian population and could be critical first-hand data to the clinicians concerned to prevent complications during surgical procedures and nerve block. In addition, these findings may help prevent the involvement of neurovascular structures that cross these foramina in surgical procedures in the periorbital region. Because of the numerous variations of the exit points on the supraorbital rim, all surgical approaches to the supraorbital nerve on the supraorbital rim, especially the endoscopic ones, have to be done under proper vision and with the utmost care of the nerves. The incidence of ASOF is common. It is more frequently seen lying lateral to the main SOF/SON. This should be kept in mind while performing these procedures.

The differences found in the current study alert surgeons to prevent anesthetic errors and other procedures involving SOF. Therefore, the risks associated with facial surgery may be reduced for the Indian population if the anatomic morphometry is taken into consideration. The data are of utmost relevance for clinical practice and teaching.

\section{CLINICAL RELEVANCE}

- Multiplicity of facial foramina is associated with the branching of developing nerves and may explain a few cases of failure during infiltrative anesthesia for maxillofacial procedures

- Thus, knowledge of the distance between the SOF and ASOF is useful in identifying the location of the danger zone during dissection of the fracture of orbital margins and plastic surgeries near superior orbital wall.

\section{ACKNOWLEDGMENT}

We acknowledge the kind support of administration and technical staff in helping us to carry out the study in cordial manner.

\section{AUTHORS' CONTRIBUTIONS}

Subhash Gupta and Kamta Nirala designed the model and the computational framework, analyzed the data, and carried out the implementation. Amrita Gupta and Sagun Shukla performed the calculations, discussed the results, and review the final manuscript with input from all authors.

\section{CONFLICTS OF INTEREST}

None.

\section{AUTHORS' FUNDING}

Self.

\section{REFERENCES}

1. Sicher H, Dubrul EL. Sicher and Dubrul Oral Anatomy. $8^{\text {th }}$ ed. St. Louis: Ishiyaku EuroAmerica Inc.; 1991.

2. Williams PL, Bannister LH, Berry MM, Collins P, Dyson M, Dusseck JE, Ferguson MW, editors. Exterior of the skull. In: Gray's Anatomy. $38^{\text {th }}$ ed. New York: Churchill Livingstone; 1995.

3. Cutright B, Quillopa N, Schubert W. An anthropometric analysis of the key foramina for maxillofacial surgery. J Oral Maxillofac Surg 2003;61:354-7.

4. Saylam C, Ozer MA, Ozek C, Gurler T. Anatomical variations of the frontal and supraorbital transcranial passages. J Craniofac Surg 2003;14:10-2.

5. Beer GM, Putz R, Mager K, Schumacher M, Keil W. Variations of the frontal exit of the supraorbital nerve: An anatomic study. Plast Reconstr Surg 1998;102:334-41.

6. Canan S, Asim ÖM, Okan B, Ozek C, Alper M. Anatomic variations of the infraorbital foramen. Ann Plast Surg 1999;43:613-7.

7. Gupta T. Localization of important facial foramina encountered in maxilla -facial surgery. Clin Anat 2008;21:633-40.

8. Hollinshed WH. The head and neck. In: Anatomy for Surgeons. Philadelphia, PA: Harper and Row; 1982.

9. Kazkayasi M, Ergin A, Ersoy M, Tekdemir I, Elhan A. Microscopic anatomy of the infraorbital canal, nerve and foramen. Otolaryngol Head Neck Surg 2003;129:692-701.

10. Standring S, Ellis H, Healy JC, Johnson D, Williams A, Collins P, editors. Gray's Anatomy: The Anatomical Basis of Clinical Practice. $39^{\text {th }}$ ed. London: Elsevier, Churchill Liwingstone; 2005. p. 511-3.

11. Webster RC, Guant JM, Hamdan US, Fuleihan NS, Giandello PR, Smith RC. Supraorbital and supratrochlear notches and foramina: Anatomical variations and surgical relevance. Laryngoscope 1986;96:311-5.

12. Huanmanop T, Agthong S, Chentanez V. Surgical anatomy of fissures and foramina in the orbits of Thai adults. J Med Assoc Thai 2007;90:2383-91.

13. Guyuron B, Kriegler JS, Davis J, Amini SB. Comprehensive surgical treatment of migraine headaches. Plast Reconstr Surg 2005;115:1-9.

14. Janis JE, Ghavami A, Lemmon JA, Leedy JE, Guyuron B. The anatomy of the corrugator supercilii muscle: Part II. Supraorbital nerve branching patterns Plast Reconstr Surg 2008;121:233-40.

15. Ashwini LS, Mohandas Rao KG, Saran S, Somayaji SN. Morphological and morphometric analysis of supraorbital foramen and supraorbital notch: A study on dry human skulls. Oman Med J 2012;27:129-33.

16. Ongeti K, Hassanali J, Ogengo J, Saidi H. Biometric features of facial foramina in adult Kenyan skulls. Eur J Anat 2008;12:89-95.

17. Berry AC, Berry RJ. Epigenetic variation in the human cranium. J Anat 1967:101:361-79.

18. Chrcanovic BR, Abreu MH, Custodio AL. A morphometric analysis of supraorbital and infraorbital foramina relative to surgical landmarks. Surg Radiol Anat 2011;33:329-35. 